\title{
Saúde mental e economia solidária: a experiência de usuários e trabalhadores de um CAPS II ${ }^{1}$
}

\author{
Ioneide de Oliveira Campos ${ }^{a}$, Yasmim Bezerra Magalhães ${ }^{\mathrm{b}}$, Pamela Kikuchi ${ }^{\mathrm{a}}$, \\ Pedro de Andrade Calil Jabur ${ }^{a}$, Fabíola Rebouças ${ }^{c}$, Girlene Marques Pinheiro \\ ${ }^{a}$ Faculdade de Ceilândia, Universidade de Brasília - UnB, Brasília, DF, Brasil.

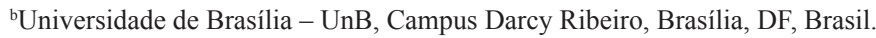 \\ ${ }^{c}$ Centro de Atenção Psicossocial de Taguatinga, Secretaria Estadual do Distrito Federal, Brasília, DF, Brasil.
}

\begin{abstract}
Resumo: Este trabalho insere-se no contexto das discussões sobre saúde mental e economia solidária. Trata-se de um relato de experiência vivenciada no Centro de Atenção Psicossocial de Taguatinga II (CAPS) - Distrito Federal, onde os projetos desenvolvidos para geração de trabalho e renda na área de saúde mental reafirmam a capacidade que têm, como instrumentos para inclusão social, de incorporar princípios e valores da economia solidária com vistas ao empoderamento e autonomia dos cidadãos em sofrimento mental. Pretendeu-se, com este trabalho, fomentar e subsidiar reflexões acerca das possibilidades de inclusão social decorrentes da geração de trabalho e renda por meio de ações coletivas e solidárias, elaboradas/construídas com a participação de usuários, familiares e trabalhadores nesse serviço. A ênfase na metodologia participativa norteou o desenvolvimento da experiência, sendo que a proposição de ações disparadoras sobre saúde mental e economia solidária em diversos momentos, sob coordenação da equipe executora, proporcionou, concomitantemente, a realização de duas ações/intervenções: atividade grupal destinada a usuários e familiares do serviço, que se reuniram para conhecer e refletir sobre trabalho coletivo e empreendimento solidário; e três capacitações mensais, de agosto a dezembro de 2013, sobre cooperativismo, economia solidária e saúde mental, direcionadas aos trabalhadores do referido CAPS. Observou-se, ao final, que o envolvimento de pessoas em sofrimento mental nesses projetos contribui para superação do atual estado de subordinação e fragilidade. Acresce-se que o desenvolvimento dessas ações favoreceu, de modo geral, reflexões sobre o mundo do trabalho coletivo e agregou conhecimento metodológico sobre empreendimentos solidários.
\end{abstract}

Palavras-chave: Desinstitucionalização, Saúde Mental, Trabalho, Autonomia Pessoal.

\section{Mental health and solidarity economy: the experience of users and workers of a Psychosocial Care Center}

\begin{abstract}
This work is within the context of discussions on mental health and solidarity economy. It is an account of the experience lived at the Tabatinga II Psychosocial Care Center (CAPS) in the Federal District, Brazil, where projects designed to generate employment and income in the mental health area reaffirm their ability, as tools for social inclusion, to incorporate the principles and values of solidarity economy aiming at the empowerment and autonomy of citizens in mental distress. This work intended to support and encourage reflections on the possibilities for social inclusion arising from the generation of jobs and income through collective and cooperative actions developed and elaborated with the participation of users, family members, and workers of this service. Emphasis on participatory methodology guided the development of the experience, and the proposition of triggering actions on mental health and solidarity economy at different times, under the coordination of the performing team, afforded, concurrently, the realization of two actions/interventions: a group activity designed to service users and their relatives who gathered to learn and reflect on collective work and supportive venture; and three monthly training
\end{abstract}

Autor para correspondência: Ioneide de Oliveira Campos, Faculdade de Ceilândia, Universidade de Brasília, Centro Metropolitano, conjunto A, lote 01, CEP 72220-900, Brasília, DF, Brasil, e-mail: ioncampos@hotmail.com 
sessions, from August to December 2013, on cooperativism, solidarity economy, and mental health addressed to the professionals of that CAPS. At the end of these interventions, it was possible to observe that the involvement of people under mental distress in these projects contributes to overcome their current state of subordination and weakness. It is worth mentioning that, in general, the development of these actions favored reflections on the world of collective work and aggregated methodological knowledge on solidarity ventures.

Keywords: Deinstitutionalization, Mental Health, Work, Personal Autonomy.

\section{Introdução}

As transformaçóes do modelo de cuidado em saúde mental desencadearam e possibilitaram o desenvolvimento de uma nova prática em saúde mental, marcada pelo princípio do território, isto é, um cuidado pautado na busca pela validação dos direitos das pessoas em sofrimento psíquico, na disponibilidade dos serviços e na priorização de investimentos nos projetos de vida dos usuários e aumento do seu poder contratual.

Fortemente influenciada pela experiência italiana de Psiquiatria Democrática, a Reforma Psiquiátrica brasileira apontou a necessidade de se repensar a situaçáo em que se encontravam os pacientes psiquiátricos, buscando novas alternativas de assistência. Como consequência, foram criadas estratégias territoriais, tais como os Centros de Atenção Psicossocial (CAPS), e realizadas formulaçóes políticas que contribuíram para avanço desse importante processo de mudança. Destaca-se que, atualmente, o CAPS é considerado um dispositivo estratégico da política de saúde mental (BRASIL, 2004).

Vale mencionar que a Reforma Psiquiátrica foi um movimento que teve início nas décadas de 60 e 70, em vários países europeus e EUA, impulsionada por abordagens ora psicanalíticas (DESVIAT, 1999), por vezes de bases essencialmente sociais (BASAGLIA, 1985). Alguns desses movimentos tinham como objetivo substituir o modelo assistencial centrado no hospital psiquiátrico pelo de serviços abertos no território, com inclusão do sujeito nos planos dos direitos e do convívio social (DESVIAT, 1999). A partir dos anos 80, inspirado pelas ideias da Psiquiatria italiana, esse movimento ganhou materialidade no contexto brasileiro, com diversas experiências comunitárias de cuidado em saúde mental.

No atual cenário da reforma psiquiátrica, os desafios são cotidianos e a discussão de estratégias reabilitadoras torna-se instrumento potente voltado à inserção social de usuários em saúde mental, na perspectiva da reabilitação psicossocial.

É nesse contexto que se encontra espaço para refletir sobre a inclusão social, particularmente por meio do trabalho, questão ainda incipiente no campo da saúde mental, embora algumas experiências exitosas (NICÁCIO et al., 2005) de inserção dos usuários no contexto brasileiro demonstrem uma melhor qualidade de vida e efetividade nos projetos terapêuticos dos usuários.

Definida como um conjunto de estratégias direcionadas a aumentar as possibilidades de trocas, valorizando o sujeito e seu contexto, a reabilitação psicossocial propóe uma abordagem focada na contratualidade dos usuários, o que implica a necessidade ética de contemplar três vértices da vida de qualquer cidadão: casa, trabalho e lazer (SARACENO, 1999). Traz a ideia do poder de negociaçáo, a construçáo da contratualidade no cotidiano (KINOSHITA, 2001). O eixo trabalho diz respeito à possibilidade de produção e troca de mercadorias e valores como um dos cenários importantes na vida dos usuários e, portanto, há necessidade de direcionar açôes de reabilitação para esse aspecto. Todavia, "o lugar real do trabalho na organização de assistência à doença mental é ainda bastante precário" (SARACENO, 1999, p. 131). É justamente com o propósito de reduzir a precariedade e a desvantagem social que os projetos de geração do trabalho e renda na área saúde mental têm incorporado princípios da economia solidária.

A Secretaria Nacional de Economia Solidária define a economia solidária como uma forma diferente de produzir, vender, comprar e trocar o que é preciso para viver. Sem explorar os outros, sem querer levar vantagem, sem destruir o ambiente, cooperando, fortalecendo o grupo, cada um pensando em si e também no bem de todos. Pode-se ainda mencionar que, nos últimos anos, a economia solidária vem se apresentando como alternativa de geração de trabalho e renda e instrumento a favor da inclusão social. Compreende uma variedade de práticas econômicas e sociais organizadas sob a forma de cooperativas, associações, clubes de troca, empresas autogestionárias, redes de cooperação, entre outras, que realizam atividades de produção de bens, prestação de serviços, finanças solidárias, trocas, comércio justo e consumo solidário (BRASIL, 2012). 
Dessa maneira, a economia solidária, como resposta à exclusão pelo mercado (SINGER, 2005), apresenta-se como possibilidade de produzir sentido para as pessoas em sofrimento mental, favorecendo que desenvolvam sua autonomia e, na medida do possível, possam planejar o próprio trabalho e participem do processo de gestão. Assim, a luta pela inclusão social e econômica de pessoas com transtornos mentais é objetivo da economia solidária e do movimento da reforma psiquiátrica, isto é, ambos nascem de uma mesma razão (BRASIL, 2005).

Este trabalho tem como objetivo realizar um relato de experiência das atividades de um projeto de extensão, desenvolvido em 2013 em um Centro de Atenção Psicossocial, com os propósitos principais de fomentar e subsidiar a reflexão a respeito das possibilidades de inclusão social de geração e renda por meio de açóes coletivas e solidárias com a participação de usuários, familiares e profissionais do referido serviço.

\section{Percurso metodológico}

O cenário deste projeto foi o Centro de Atenção Psicossocial II de Taguatinga (CAPS), da cidade de Taguatinga - Distrito Federal. Trata-se de um serviço realizado em uma casa localizada na regiáo central de Taguatinga, ligado à Secretaria de Estado da Saúde do Distrito Federal e inserido na Gerência de Saúde Mental-GESAM. Inaugurado em dezembro de 2006, conta com equipe administrativa e técnica (enfermeiros, assistentes sociais, psicólogos, terapeutas ocupacionais e psiquiatras). A realização de oficinas e grupos terapêuticos sáo as principais formas de atenção às pessoas em sofrimento.

A parceria entre a Universidade de Brasília e o CAPS II de Taguatinga, com financiamento do Ministério da Educação, desenvolveu-se no período de março a dezembro de 2013, com destaque para duas atividades realizadas durante o projeto: 1) Sensibilização de trabalhadores do serviço sobre a temática do cooperativismo, economia solidária e saúde mental, por meio de três capacitações oferecidas para à equipe; 2) Formação de um grupo semanal com usuários e familiares.

Sobre a realização das capacitaçóes previstas no projeto, a equipe aderiu à proposta e as datas foram decididas coletivamente, optando-se por realizá-las no horário das reuniōes da equipe técnica. A criação e a constituição grupal tiveram apoio técnico de uma terapeuta ocupacional do serviço que, $a$ priori, já tinha uma demanda, ou seja, uma lista de usuários e familiares interessados em discutir questóes referentes à economia solidária e saúde mental. Além disso, foi realizada busca ativa de usuários e familiares, em diversos grupos e oficinas ofertados pelo serviço, e divulgado o projeto, por meio de folhetos impressos, na recepção do CAPS. Com a planilha de interessados, fez-se contato telefônico com todos os possíveis participantes e os trabalhos do grupo foram iniciados com o quantitativo de 15 usuários, não havendo adesão de familiares ao grupo. Destes, 13 usuários mantiveram-se, na medida do possível, assíduos ao longo do processo. Chegou-se a um total de 18 encontros semanais, norteados pela premissa de subsidiar as discussóes e açóes nas dimensóes coletivas e solidárias.

Nos primeiros meses, a equipe executora do projeto reuniu-se para organizar e planejar as atividades que seriam desenvolvidas, bem como para discutir o cronograma para realização das capacitaçóes com a equipe técnica e formular a dinâmica de condução do grupo de usuários, de modo a permitir que ele acontecesse da maneira mais autônoma possível para esses indivíduos. Foram introduzidos temas fundamentais para a formação e construção de saberes em economia solidária.

Com o intuito de auxiliar essas discussóes, utilizou-se um caderno das memórias sobre os encontros com o grupo de usuários e foram feitas anotaçóes sobre as capacitaçóes oferecidas para a equipe do serviço. Essas informações permitiram traçar os resultados obtidos por usuários e trabalhadores do serviço após as intervençóes previstas.

\section{Resultados e discussão}

Embora com objetivos distintos, as intervençóes foram concomitantemente iniciadas por meio de açóes interconectadas. Se, para o grupo, a proposta era subsidiar discussóes nos eixos da economia solidária e explorar as potencialidades dos envolvidos para realização de açóes coletivas e solidárias com o intuito de viabilizar oportunidades de geração de trabalho e renda, para a equipe técnica do CAPS o desafio era sensibilizar e instrumentalizar a respeito do cooperativismo, economia solidária e saúde mental, por meio de capacitaçóes ofertadas, de modo a expor o compromisso e as possibilidades do serviço e do território na execução de atividades de geração de trabalho e renda para a população atendida. A seguir, será relatado o processo grupal que envolveu usuários do serviço. 


\subsection{A dinâmica do processo grupal desenvolvido com usuários do serviço}

Importante mencionar que o perfil dos usuários, no que se refere às experiências de trabalho, era diverso. Observou-se que alguns realizaram, e ainda realizam, atividades informais (venda de artesanatos, pinturas de casa e cerâmicas). No entanto, outros traziam experiências de trabalho ao longo da vida, como recepção em clínica de especialidade médica e emprego doméstico. Algumas pessoas estavam afastadas pelo INSS e outra trabalhava em serviços gerais de uma escola da rede pública. Foi possível notar que as relações de trabalho ao longo da vida eram fragilizadas e o impacto do sofrimento mental na vida cotidiana desses usuários afetou filhos, companheiros e as suas próprias perspectivas de trabalho.

O grupo iniciou-se em um processo formativo e experimental, na presença da docente coordenadora do projeto, da terapeuta ocupacional do serviço e de duas discentes que atuaram na condição de facilitadoras do processo. Os primeiros encontros serviram para exploração de conceitos importantes em torno da economia solidária, entre eles noção de trabalho coletivo, comércio justo, cooperativismo e associativismo. Outros elementos que mobilizaram esses primeiros momentos foram os relatos das experiências de trabalho de cada sujeito e a troca de saberes quanto às potencialidades e habilidades para execução de suas tarefas.

Logo nas primeiras semanas emergiram sentimentos de coletividade no grupo, que decidiu levar para os encontros situaçóes em que pudessem apresentar os artesanatos produzidos e ensinar uns aos outros. Importante destacar também o grande interesse, sempre valorizado, para que o grupo assumisse sua própria condução, exercendo sua autonomia para revelar interesses e tomada de decisóes por meio da aproximação com os princípios da economia solidária e experiências vivenciadas nessa área.

Assim, antes mesmo do esperado, as regras do grupo, discutidas e elaboradas em conjunto no início dos encontros, passaram a ser por eles cobradas e, a cada encontro, surgiam sugestôes do próprio grupo, o que já revelava certa apropriaçáo do espaço voltado à exploração de subjetividades, construção horizontal de conhecimento e avaliação de oportunidades no território para exercerem estratégias de geração de trabalho e renda.

O diagnóstico de avaliação das potencialidades de trabalho no grupo baseou-se, predominantemente, no desenvolvimento de atividades de artesanato, que se tornaram fonte de renda para muitos após o afastamento social decorrente da situaçáo de sofrimento mental na qual se encontravam. Acresce-se que essas atividades configuraram um recurso de valorização desses sujeitos, que nem sempre conseguem dar significação às tarefas que desempenham. Assim, os usuários solicitaram à direção do CAPS e aos facilitadores que viabilizassem uma visita à Casa do Artesão, com o intuito de solicitarem a carteira do artesão e, entâo, poderem identificar os recursos disponíveis para construçáo de um trabalho coletivo. Diante desse interesse, definiu-se uma data, anteriormente prevista para um dos encontros, para a ida, de metrô, à Casa do Artesão, o que reafirmou o processo autônomo de inclusão desses sujeitos em um espaço de participaçáo social. $\mathrm{Na}$ ocasiáo, dos 13 usuários participantes do grupo, 7 preencheram o cadastro para aquisição da carteira de artesão.

Os vínculos tornaram-se mais fortes no grupo à medida que a troca de habilidades para confecção dos artigos artesanais consolidou-se entre eles. Nesse sentido, destaca-se a articulaçáo do CAPS com os organizadores de uma feira de exposiçóes da Região Administrativa (RA) de Taguatinga, o que possibilitou a criaçáo de um elo e a expansão do espaço de atuaçáo desses indivíduos para além do CAPS, fomentando ainda a comercialização de produtos que, por vezes, elaboravam, mas não sentiam que eram valorizados.

Esse momento revelou que o grupo possuía já um funcionamento próprio, com divisão de tarefas, iniciativa para arrecadação de um fundo ("caixinha”) para reposição de mercadorias e sugestão de oferecer uma parte dos lucros aos usuários que ficavam na venda dos produtos por não apresentarem afinidade com a produçáo de artesanatos. Foram realizadas três exposiçōes na feira, com uma dinâmica de organizaçáo de tarefas distribuídas coletivamente, de acordo com habilidades e desejos. Elaboraram, ainda, uma escala para definir os responsáveis pelas vendas por período, montagem e desmontagem da barraca, cuidado e responsabilidade pelo caixa e organização dos produtos a serem expostos.

Após essa organização para o trabalho coletivo, o grupo evoluiu consideravelmente para um processo ativo, aproximando-se da conquista de um espaço social e da legitimação da cidadania e diretos dos usuários de saúde mental. Passaram, então, a promover um espaço de descobertas e exploração dos recursos, no território no qual estáo inseridos, para consolidaçáo das propostas trabalhadas nas reuniōes do projeto. Atualmente, o grupo continua seu processo, em encontros semanais em um centro de convivência, sob coordenaçáo da assistente social do CAPS de Taguatinga. 


\section{Considerações finais}

Os desafios para consolidaçáo da Reforma Psiquiátrica são inúmeros e, nesse sentido, a inclusão das estratégias de economia solidária e de projetos para geração de trabalho e renda é eixo fundamental na construção permanente do lugar social dos usuários de saúde mental. Indispensável considerar que a formação das equipes de saúde mental nessa temática amplia as possibilidades de execução de atividades com características inclusivas por meio de açôes coletivas e solidárias.

A experiência no CAPS de Taguatinga permitiu aos trabalhadores e usuários acessarem um território assistencial aberto para a atribuição de novos sentidos na vida dos sujeitos, que, sobretudo, devolve e cria possibilidades de participação social autônoma, com a singularidade que cada indivíduo identifica para o trabalho.

Esses aspectos puderam ser percebidos principalmente no último encontro do grupo, ao término do projeto, quando cada um revelou seu sentimento de valorização, o que possibilitou que pudessem também se deparar com um potencial até então desconhecido. Nesse sentido, participar da feira de exposiçóes mostrou que também pertencem a esse espaço, coletivo, que muitos deixaram de frequentar. Consequentemente, houve um resgate de histórias, de crenças, de desejos e, principalmente, o reconhecimento, no outro, das possibilidades coletivamente conquistadas, trazendo a marca única dos atores que a produzem.

Os resultados aqui apresentados destacam a importância de expandir açóes como essa para que seja garantido aos usuários de saúde mental um resgate de papéis e de constituição enquanto sujeitos pertencentes a um espaço social, com oportunidades emergentes e com a necessidade de conexão com a rede social, que muitas vezes é fragilizada e empobrecida, distanciando esses indivíduos da apropriação de uma cidadania que motiva tantas outras possibilidades em seu meio.
Por fim, a constituição de um processo formativo em economia solidária, que contemple os atores envolvidos - usuários, familiares e trabalhadores - deve ser um investimento contínuo para que possa, de fato, contribuir para o desenvolvimento da economia solidária.

\section{Referências}

BASAGLIA, F. A instituição negada: relato de um hospital psiquiátrico. Rio de Janeiro: Ediçốes Graal, 1985.

BRASIL. Ministério da Saúde. Economia solidária. Brasília, 2005. Disponível em: <http://portal.saude.gov.br/portal/ arquivos/pdf/saude_mental_economia_solidaria.pdf $>$. Acesso em: 1 dez. 2013.

BRASIL. Ministério da Saúde. Secretaria de Atenção à Saúde. Departamento de Açóes Programáticas Estratégicas. Saúde mental no SUS: os centros de atençáo psicossocial. Brasília, 2004.

BRASIL. Ministério do Trabalho e Emprego. Secretaria Nacional de Economia Solidária. O que é economia solidária? Disponível em: <http://portal.mte.gov.br/ ecosolidaria/o-que-e-economia-solidaria.htm $>$. Acesso em: 27 mar. 2012.

DESVIAT, M. A reforma psiquiátrica. Rio de Janeiro: Fiocruz, 1999.

KINOSHITA, R. T. Contratualidade e reabilitação psicossocial. In: PITTA, A. Reabilitação psicossocial no Brasil. São Paulo: Hucitec, 2001. p. 55-59.

NICÁCIO, F. N.; MANGIA, E. F.; GHIRARDI, M. I. G. Projetos de inclusão no trabalho e emancipação de pessoas em situaçáo de desvantagem: uma discussão de perspectivas. Revista de Terapia Ocupacional da Universidade de São Paulo, São Paulo, v. 16, n. 2, p. 62-66, 2005.

SARACENO, B. Libertando identidades: da reabilitação psicossocial à cidadania possível. Rio de Janeiro: Instituto Franco Basaglia/Te Cora, 1999.

SINGER, P. Conferência de abertura: economia solidária e saúde mental. In: BRASIL. Ministério da Saúde. Secretaria de Atenção à Saúde. Departamento de Ações Programáticas Estratégicas. Saúde Mentale economia solidária: inclusão social pelo trabalho. Brasília, 2005. p. 11-12. Disponível em: $<$ http://www.cooperativismopopular.ufrj. br/saudemental/pdf/Saude_Mental_Economia_Solidaria. pdf $>$. Acesso em: 8 abr. 2014.

\section{Contribuição dos Autores}

Ioneide de Oliveira Campos, Yasmim Bezerra Magalháes, Pamela Kikuchi, Pedro de Andrade Calil Jabur trabalharam na concepção e redação do texto; Fabíola Rebouças e Girlene Marques Pinheiro trabalharam na organização dos dados. Todos os autores aprovaram a versão final do texto.

\section{Notas}

${ }^{1}$ Artigo inédito, integra o Projeto de Extensão (PROEXT 2013) Saúde Mental e Economia Solidária: subsídios ao desenvolvimento de açôes coletivas e solidárias. Coordenação da Profa. Ioneide de Oliveira Campos e vice-coordenação de Pedro de Andrade Calil Jabur, com financiamento do Ministério da Educaçáo - MEC/SESU. 